\title{
SEVERIDADE DO SINTOMA DA BACTÉRIA XYLELLA FASTIDIOSA EM CULTIVARES DE CAFEEIRO ${ }^{(1)}$
}

\author{
RACHEL BENETTI QUEIROZ-VOLTAN ${ }^{(2)}$; LUCIANE PEROSIN CABRAL ${ }^{(3)}$; \\ OSVALDO PARADELA FILHO ${ }^{(4)}$
}

\begin{abstract}
RESUMO
A bactéria Xylella fastidiosa tem sido estudada no cafeeiro desde que foi detectada pela primeira vez nessa cultura; entretanto, não se sabe ainda avaliar seu efeito, uma vez que o cafeeiro, provavelmente, convive com a bactéria há muitos anos e parece suportar esse patógeno em determinadas situações. O objetivo deste trabalho foi avaliar a severidade dos sintomas de infecção provocados pela X. fastidiosa sobre cultivares de Coffea arabica, enxertados ou não, a fim de estimar os níveis dos sintomas externos em diferentes tratamentos desenvolvidos em uma mesma condição edafoclimática, ao longo de diferentes períodos do ano com variação na disponibilidade de água e locais. A severidade do sintoma da bactéria foi avaliada utilizando-se uma escala de notas de 1 a 4, de acordo com a porcentagem de danos à planta, sendo a nota 4 a mais severa. Não houve diferenças no nível de severidade entre as cultivares avaliadas em Mococa e Garça no período de estresse hídrico, porém, no período de chuvas o sintoma foi mais severo em 2000 nas cultivares Catuaí e Mundo Novo não enxertadas em relação às enxertadas. A 'Catuaí' não enxertada apresentou severidade maior em Mococa do que em Garça. A seca ocorrida em Garça em 2002 foi muito mais prolongada e severa do que a de 2000 e de 1998 em Mococa. Porém, a severidade em 2002 em Garça foi menor em relação às demais, demonstrando que o déficit hídrico não é o único fator determinante dos sintomas externos da bactéria, mas outros fatores de estresse fisiológicos ou ambientais provavelmente interagem na resposta da planta.
\end{abstract}

Palavras-chave: cafeeiro, morfologia, Xylella fastidiosa, severidade do sintoma, variação sazonal.

\section{ABSTRACT \\ SEVERITY SYMPTOMS OF XYLELLA FASTIDIOSA ON COFFEE CULTIVARS}

The Xylella fastidiosa bacteria has been more intensively studied in coffee plants since the first time it was noticed infecting this specie. However, it is not well known the damages it causes, once both bacteria and hostplant can co-habit for long periods (several years), as coffee plants seems to support this pathogen under determined conditions. The main objective of this work was to study the severity of the X. fastidiosa infection on grafted or not grafted coffee plants, evaluating external symptoms in several cultivars, grown under field conditions in two contrasting environments. The symptoms were evaluated in a notation scale of 1 to 4 , being 4 given to the most severe symptoms. Under moisture stress in both Mococa and Garça, there were no differences among cultivars, however, during the rainy period, symptoms were more intense in 'Catuai' and 'Mundo Novo' not grafted cultivars during the 2000 growth season, as compared to the grafted ones. Not grafted 'Catuaí' was more severely attacked in Mococa than in Garça. The 2002 drought period in Garça was much longer and more severe than that of 2000 and 1998 in Mococa. However, there was less severe symptoms in Garça in 2002 demonstrating that

$\left({ }^{1}\right)$ Com recursos complementares do Consórcio Brasileiro de Pesquisa e Desenvolvimento do Café. Recebido para publicação em 17 de fevereiro e aceito em 24 de junho de 2004.

$\left({ }^{2}\right)$ Núcleo de Pesquisa e Desenvolvimento do Jardim Botânico/Centro Experimental Central/IAC, Caixa Postal 28, 13001-970 Campinas (SP). E-mail: rachelqv@iac.sp.gov.br

$\left(^{3}\right)$ Bolsista do Consórcio Brasileiro de Pesquisa e Desenvolvimento do Café.

$\left({ }^{4}\right)$ Centro de Pesquisa e Desenvolvimento de Fitossanidade/IAC. 
moisture deficit is not the sole factor determining external bacterial symptoms, other physiological and environmental stresses and its interaction might probably play an important role in the coffee plant response to this bacteria infection.

Key words: coffee plants, morphology, Xylella fastidiosa, severity symptoms, seasonal variations.

\section{INTRODUÇÃO}

A presença da bactéria Xylella fastidiosa Wells et al., no Estado de São Paulo, foi relatada no cafeeiro por Paradela Filho et al. $(1995,1997)$. Desde então, diversos trabalhos têm sido desenvolvidos para o conhecimento da relação patógeno-hospedeiro (LiMA et al., 1996; QueIroz-Voltan et al., 1998).

Os sintomas morfológicos externos apresentados pelas plantas infectadas são os seguintes: encurtamento dos entrenós e, com o agravamento da doença, senescência foliar precoce na base dos ramos, resultando em pequeno número de folhas no ápice. Esses ramos também apresentam pecíolos e área foliar reduzidos e frutos menores e agrupados, em vista de encurtamento dos pedicelos e dos entrenós (Paradela Filho et al., 1995). Internamente, ocorre uma deposição de "goma" nos vasos do xilema, assim como divisões anormais no mesofilo e no xilema, floema e córtex do pecíolo e do caule de ramos que apresentam muito sintoma externo de infecção. As células do mesofilo das folhas de cafeeiro afetadas também apresentam número reduzido de cloroplastos, associado à maior concentração de cristais de oxalato de cálcio (QueIrozVOLTAN et al., 1998).

Segundo Paradela Filho et al. (1997), há muitos anos o cafeeiro vem apresentando sintomas de infecção pela $X$. fastidiosa, os quais, entretanto, eram atribuídos a um esgotamento nutricional devido a altas produções. Esses autores consideram, ainda, que a bactéria foi disseminada de plantas de cafeeiro para as de laranjeira no Brasil, devido à presença da bactéria em cafeeiro em regiões onde não havia plantações de citros, à presença da clorose variegada de citros em lavouras que sucederam a cultura cafeeira e à similaridade dos vetores transmissores dessa bactéria. O efeito dessa bactéria na anatomia da planta foi descrito por QueIROz-VolTAN et al. (1998), e discutiu-se a forte evidência de uma relação entre a $X$. fastidiosa e senescência, associadas a fatores de estresse.

$X$. fastidiosa vem causando prejuízos a culturas econômicas importantes, desde 1892, na Califórnia, quando foi detectada na videira (PIERCE, 1892). Diversas culturas de regiões climáticas tropicais e subtropicais como a alfafa (GoHeEN et al., 1973), pessegueiro (HopKINs et al., 1973; NYLAND et al.,1973), amendoeira (Mircetich et al., 1976), ameixeira (HopKINS, 1989), citros (CHAGAs et al., 1992) e outros hospedeiros de menor interesse (Hopkins $\mathrm{E}$ ADLERZ,1988) também apresentaram problemas causados por essa bactéria. No Brasil, tem causado prejuízos até de $35 \%$ na cultura de citros, enquanto na cafeicultura, embora não tenha sido quantificada sua significância econômica, registrou-se em São José do Rio Preto (SP) uma redução de $30 \%$ na produção em algumas plantações (PrATO, 2000).

A transmissão é feita através de cigarrinhas das famílias Cicadellidae (subfamília Cicadellinae) e Cercopidae que se alimentam dos ramos e folhas (Hopkins, 1989; Lopes, 1996; PAIVA et al., 1996) e pouco se conhece sobre a relação patógeno-hospedeiro em cafeeiro.

O objetivo deste trabalho foi avaliar a severidade dos sintomas de infecção provocados pela $X$. fastidiosa sobre cultivares de Coffea arabica L., enxertados ou não, para estimar os níveis dos sintomas externos em diferentes tratamentos desenvolvidos em uma mesma condição edafoclimática, ao longo de diferentes períodos do ano com variação na disponibilidade de água e locais.

\section{MATERIAL E MÉTODOS}

O estudo foi efetuado em experimento de cafeeiro enxertado, instalado em 1986, no Pólo Regional de Desenvolvimento Tecnológico do Nordeste Paulista, em Mococa (latitude $21^{\circ} 29^{\prime} \mathrm{S}$, longitude $47^{\circ}$ $01^{\prime} \mathrm{W}$ e altitude $665 \mathrm{~m}$ ) e na Fazenda da Mata, município de Garça (latitude $22^{\circ} 12^{\prime} \mathrm{S}$, longitude $49^{\circ}$ $39^{\prime} \mathrm{W}$ e altitude $663 \mathrm{~m}$ ), ambos no Estado de São Paulo. Portanto, essas plantas estiveram disponíveis para a alimentação das cigarrinhas, transmissoras dessa bactéria, ao longo de 17 anos.

O delineamento utilizado foi o de blocos ao acaso, com dez tratamentos e cinco repetições, sendo o espaçamento de $3,5 \times 2,0 \mathrm{~m}$ e, as parcelas, de quatro covas, cada uma com duas plantas.

Como porta-enxerto, utilizaram-se duas progênies de C. canephora Pierre ex A. Froehner Apoatã IAC 2258 e IAC 2286 - e uma de C. congensis A. Froehner - IAC Bangelan coleção 5. Como enxerto, empregaram-se duas cultivares de C. arabica: Catuaí Vermelho IAC H 2077-2-5-81 e Mundo Novo IAC 515-20. 
Todas essas progênies utilizadas como portaenxertos foram oriundas de plantas matrizes, selecionadas pelo Centro de Análise e Pesquisa Tecnológica do Agronegócio do Café/IAC/APTA em áreas infestadas por nematóides. Também se efetuaram auto enxertias em Catuaí e Mundo Novo, considerando-se, como testemunha, as plantas não enxertadas dessas cultivares.

Avaliou-se a severidade do sintoma da bactéria utilizando-se uma escala de notas de 1 a 4 , de acordo com os seguintes critérios: nota 1- de 1\% a $25 \%$ dos ramos com sintoma morfológico externo de presença da bactéria (planta aparentemente sadia); 2de $26 \%$ a $50 \%$ dos ramos com sintomas (planta pouco infectada); nota $3-51 \%$ a $75 \%$ dos ramos com sintoma (planta moderadamente infectada) e nota 4 - de $76 \%$ a $100 \%$ de ramos com sintoma (planta muito infectada). Nas áreas de experimentação, não havia plantas com $0 \%$ de ramos com sintoma da presença da bactéria.

Cinqüenta plantas fizeram parte de cada amostra, pertencentes a 10 tratamentos retirados de cada uma das cinco parcelas. Confirmou-se a presença da bactéria nessas plantas, apesar da evidência morfológica externa descrita anteriormente ter sido observada, por meio de microscopia ótica e eletrônica. As amostras de Mococa foram avaliadas apenas no período de estresse hídrico em abril de 1998; as de Garça, no período de estresse hídrico em abril de 2000 e maio de 2002; no período chuvoso, em novembro de 2000 e 2002. Em outubro de 2002, as plantas foram submetidas à poda do tipo decote.
Os resultados foram analisados através do teste não paramétrico de Friedman (Gomes, 1990, SPRENT, 1996) e a significância do teste foi considerada a $1 \%$ e $5 \%$. A cultura do cafeeiro foi realizada nas condições ideais de adubação, calagem e de tratos culturais recomendados para seu desenvolvimento (RAIJ et al., 1997).

\section{RESULTADOS E DISCUSSÃO}

A severidade dos sintomas de presença da bactéria entre os tratamentos, enxertados ou não, no período de estresse hídrico, não diferiu em Mococa (Tabela 1) e Garça (Tabelas 2 e 3). Entretanto, no período de chuvas em 2000 em Garça (Tabela 2), que foi um ano mais seco do que 1998 em Mococa (Tabela 1), as diferenças foram significativas e a cultivar Catuaí, enxertada sobre Bangelan e Mundo Novo, sobre IAC 2286, foram os materiais genéticos que apresentaram um grau de severidade menor. Observou-se também que as cultivares enxertadas sobre $C$. canephora e $C$. congensis apresentaram severidade menores do que as que possuiam o sistema radicular de C. arabica. Em 2002 (Tabela 3), tanto no período de estresse hídrico como no de chuvas, não houve diferenças na severidade entre os tratamentos, sendo esta menor do que no ano de 2000 (Tabela 2), embora 2002 tenha sido um ano mais seco, segundo informações metereológicas do Centro de Pesquisa e Desenvolvimento de Ecofisiologia e Biofísica.

Tabela 1. Níveis de severidade ocasionados pela bactéria Xylella fastidiosa em cultivares comerciais de cafeeiro, enxertadas ou não, no período de estresse hídrico em 1998 em Mococa (SP)

\begin{tabular}{|c|c|c|c|c|c|c|c|c|c|}
\hline \multirow{2}{*}{ Tratamentos } & \multicolumn{5}{|c|}{ Parcelas } & \multirow{2}{*}{ Mediana } & \multirow{2}{*}{$\mathrm{R}$} & \multirow{2}{*}{ K1 } & \multirow{2}{*}{$\mathrm{P}$} \\
\hline & A & $\mathrm{B}$ & $\mathrm{C}$ & $\mathrm{D}$ & $\mathrm{E}$ & & & & \\
\hline Catuaí/ IAC 2258 & 2 & 3 & 2 & 2 & 1 & 1,80 & 26,0 & 8,05 & $0,529 \mathrm{NS}$ \\
\hline Catuaí/ Bangelan & 1 & 1 & 1 & 4 & 2 & 1,10 & 18,5 & & \\
\hline Catuaí/IAC 2286 & 3 & 2 & 3 & 1 & 1 & 2,00 & 25,5 & & \\
\hline Mundo Novo/IAC 2258 & 2 & 2 & 1 & 2 & 3 & 2,10 & 25,5 & & \\
\hline Mundo Novo/Bangelan & 1 & 2 & 2 & 2 & 3 & 2,00 & 24,5 & & \\
\hline Mundo Novo/IAC 2286 & 3 & 2 & 3 & 2 & 2 & 2,30 & 32,0 & & \\
\hline Catuaí/ Catuaí & 2 & 2 & 3 & 3 & 3 & 2,40 & 35,0 & & \\
\hline Mundo Novo/Mundo Novo & 2 & 2 & 2 & 1 & 3 & 1,90 & 24,0 & & \\
\hline Mundo Novo & 4 & 1 & 3 & 1 & 2 & 1,70 & 25,5 & & \\
\hline Catuaí & 2 & 3 & 3 & 2 & 4 & 2,70 & 38,5 & & \\
\hline
\end{tabular}

Notas 1: $1 \%$ a $25 \%$ de ramos com sintomas (aparentemente sadia); 2: de $26 \%$ a $50 \%$ de ramos com sintomas (pouco infectada); 3: $51 \%$ a $75 \%$ de ramos com sintomas (moderadamente infectada); $4: 76 \%$ a $100 \%$ de ramos com sintomas (muito infectada). $\mathrm{R}$ = somatório do número de ordem; $\mathrm{K} 1$ = estatística $\mathrm{K}$ ajustado; $\mathrm{P}=$ probabilidade; NS = não significativo pelo teste de Friedman. 
Tabela 2. Níveis de severidade ocasionados pela bactéria Xylella fastidiosa em cultivares comerciais de cafeeiro, enxertadas ou não, nos períodos de estresse hídrico e chuvoso, em 2000 em Garça (SP)

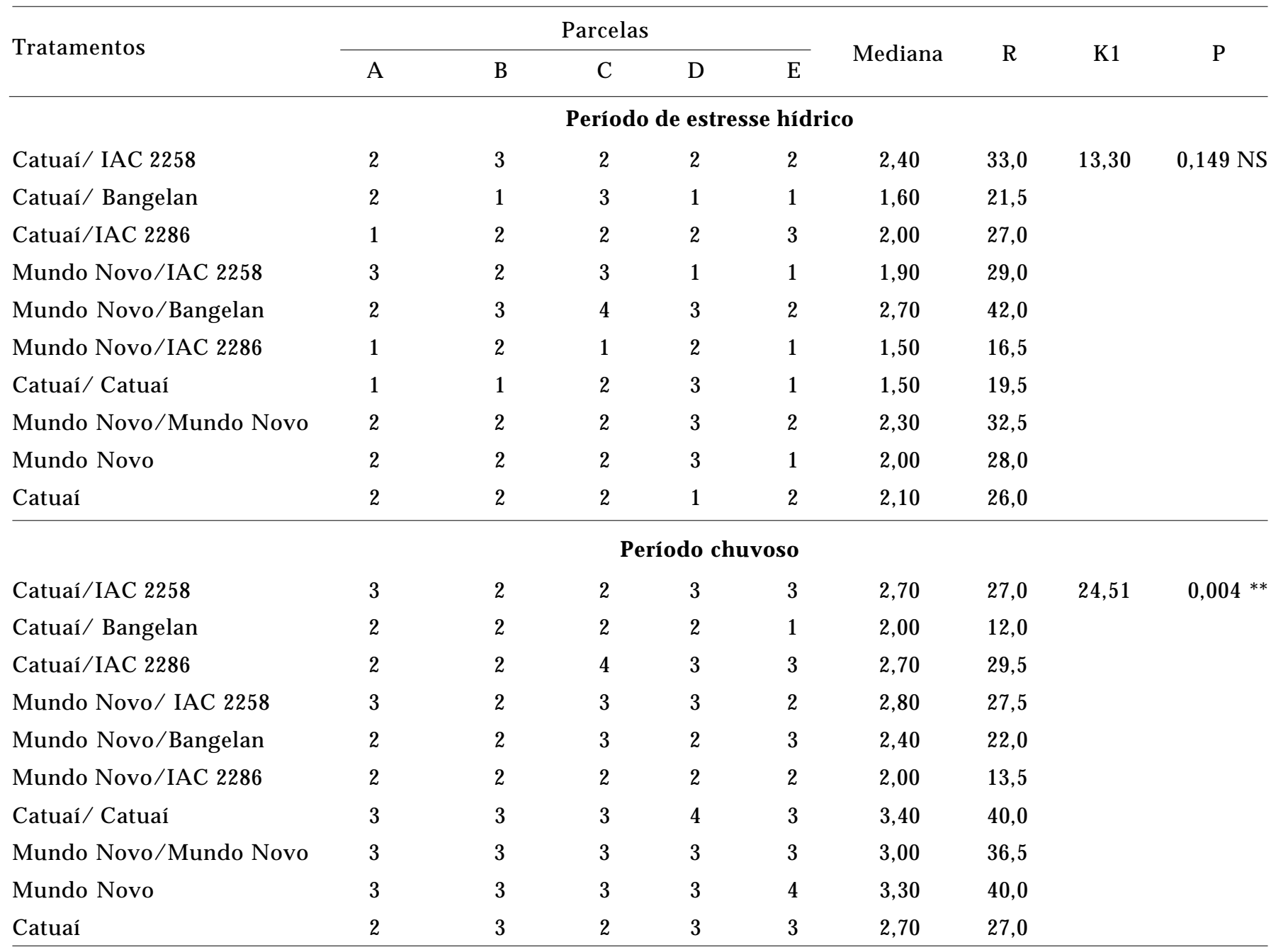

Notas 1: $1 \%$ a $25 \%$ de ramos com sintomas (aparentemente sadia); 2 : de $26 \%$ a $50 \%$ de ramos com sintomas (pouco infectada); 3: $51 \%$ a $75 \%$ de ramos com sintomas (moderadamente infectada); $4: 76 \%$ a $100 \%$ de ramos com sintomas (muito infectada). $\mathrm{R}$ = somatório do número de ordem; K1 = estatística $\mathrm{K}$ ajustado; $\mathrm{P}$ = probabilidade; NS = não significativo pelo teste de Friedman; ** = significativo a $1 \%$ pelo teste de Friedman.

Efetuou-se uma comparação entre o período de estresse hídrico de 1998, em Mococa, com o avaliado em Garça em 2000, representado na tabela 4. Apenas a 'Catuaí' enxertada sobre ela mesma e a 'Catuaí' pé-franco apresentaram diferenças significativas, sendo a maior severidade observada em Mococa. Quando se inclui na análise o período de estresse hídrico de 2002, na amostra avaliada em Garça (Tabela 5), observou-se o mesmo resultado, isto é, os sintomas externos foram mais severos em Mococa na 'Catuaí' pé-franco e na 'Catuaí' enxertada sobre ela mesma. Em Garça, a severidade em 'Catuaí' porta-enxertada sobre C. canephora IAC 2258 diminuiu em 2002.
O nível de severidade não aumentou com a maior obstrução dos vasos verificada no período de estresse hídrico (QUEIROZ-VOLTAN et al., 2000) como seria esperado; ao contrário, no período chuvoso a severidade foi maior em Garça em 2000. Comparando-se os dois anos avaliados em Garça, observou-se que a severidade foi menor em 2002, embora tenha sido um ano com índices de armazenamento de água no solo menor do que o de 2000 (Tabela 6).

Esses resultados obtidos demonstram que a disponibilidade de água não está diretamente relacionada com a severidade das plantas infectadas com a X. fastidiosa. 
Tabela 3. Níveis de severidade ocasionados pela bactéria Xylella fastidiosa em cultivares comerciais de cafeeiro, enxertadas ou não, nos períodos de estresse hídrico e chuvoso em 2002, em Garça (SP)

\begin{tabular}{|c|c|c|c|c|c|c|c|c|c|}
\hline \multirow{2}{*}{ Tratamentos } & \multicolumn{5}{|c|}{ Parcelas } & \multirow{2}{*}{ Mediana } & \multirow{2}{*}{$\mathrm{R}$} & \multirow{2}{*}{ K1 } & \multirow{2}{*}{$\mathrm{P}$} \\
\hline & A & $\mathrm{B}$ & $\mathrm{C}$ & $\mathrm{D}$ & $\mathrm{E}$ & & & & \\
\hline \multicolumn{10}{|c|}{ Período de estresse hídrico } \\
\hline Catuaí/IAC 2258 & 1 & 2 & 2 & 1 & 1 & 1,45 & 23,5 & 10,71 & 0,296NS \\
\hline Catuaí/ Bangelan & 2 & 1 & 2 & 1 & 1 & 1,45 & 23,5 & & \\
\hline Catuaí/IAC 2286 & 1 & 1 & 1 & 1 & 1 & 1,15 & 14,0 & & \\
\hline Mundo Novo/IAC 2258 & 2 & 1 & 1 & 2 & 2 & 1,95 & 28,0 & & \\
\hline M. Novo/Bangelan & 1 & 1 & 3 & 2 & 2 & 2,05 & 31,0 & & \\
\hline M. Novo/IAC 2286 & 1 & 2 & 2 & 2 & 2 & 1,95 & 32,5 & & \\
\hline Catuaí/ Catuaí & 1 & 1 & 1 & 3 & 2 & 1,65 & 26,5 & & \\
\hline M. Novo/ M. Novo & 2 & 1 & 2 & 2 & 3 & 2,05 & 36,0 & & \\
\hline Mundo Novo & 1 & 1 & 2 & 2 & 2 & 1,85 & 27,5 & & \\
\hline Catuaí & 1 & 2 & 2 & 2 & 2 & 1,95 & 32,5 & & \\
\hline \multicolumn{10}{|c|}{ Período chuvoso } \\
\hline Catuaí/IAC 2258 & 1 & 2 & 3 & 2 & 2 & 1,95 & 30,0 & 11,67 & $0,232 \mathrm{NS}$ \\
\hline Catuaí/ Bangelan & 1 & 2 & 1 & 3 & 2 & 1,95 & 26,5 & & \\
\hline Catuaí/IAC 2286 & 1 & 2 & 2 & 2 & 1 & 1,75 & 21,5 & & \\
\hline Mundo Novo/IAC 2258 & 3 & 4 & 2 & 2 & 3 & 3,15 & 40,5 & & \\
\hline M. Novo/Bangelan & 1 & 1 & 1 & 2 & 2 & 1,55 & 17,5 & & \\
\hline Catuaí/ Catuaí & 1 & 2 & 2 & 3 & 1 & 1,85 & 26,0 & & \\
\hline M. Novo/ M. Novo & 2 & 2 & 3 & 2 & 2 & 2,25 & 34,5 & & \\
\hline Mundo Novo & 1 & 2 & 2 & 2 & 2 & 1,95 & 26,0 & & \\
\hline Catuaí & 2 & 2 & 2 & 2 & 1 & 2,05 & 26,0 & & \\
\hline
\end{tabular}

Notas 1: $1 \%$ a $25 \%$ de ramos com sintomas (aparentemente sadia); 2 : de $26 \%$ a $50 \%$ de ramos com sintomas (pouco infectada); 3: $51 \%$ a $75 \%$ de ramos com sintomas (moderadamente infectada); $4: 76 \%$ a $100 \%$ de ramos com sintomas (muito infectada). $\mathrm{R}$ = somatório do número de ordem; $\mathrm{K} 1$ = estatística $\mathrm{K}$ ajustado; $\mathrm{P}$ = probabilidade; $\mathrm{NS}$ = não significativo pelo teste de Friedman .

No experimento instalado em Mococa, FAHL et al. (2001), avaliando esse material de 1994 a 1997, concluíram que as plantas enxertadas aumentavam a produção de C. arabica, pois, em condições de excesso de água no solo, a taxa fotossintética era maior nessas plantas, apesar de haver pouca diferença na transpiração e na condutância estomática.

Com o déficit hídrico no solo, na estação seca, as plantas enxertadas aumentavam sua taxa de transpiração e condutância estomática em relação às não-enxertadas e, conseqüentemente, apresentavam maior ganho de carbono. Plantas de C. arabica enxertadas sobre $C$. canephora apresentaram maior capacidade em absorver e translocar água para a parte aérea durante período de estresse hídrico no solo, em relação às plantas de C. arabica não enxertadas, porque o sistema radicular de C. canephora é mais desenvolvido (FAHL et al., 1998, 2001). Desse modo, seria esperado que o efeito da X. fastidiosa fosse menor em plantas de $C$. arabica enxertadas sobre $C$. canephora, pois diminuiria os riscos de estresse hídrico provocados pela bactéria. Essas diferenças, porém, não foram observadas entre os tratamentos.

Comparando-se o período de estresse hídrico com o de chuvas em 2000 em Garça (Tabela 6), observou-se que o nível de severidade dos sintomas de 'Catuaí' enxertada sobre ela mesma, de 'Mundo Novo' pé-franco e de 'Mundo Novo' enxertada sobre ela mesma foi menor no período de estresse hídrico do que no chuvoso. Em 2002, quase todos os tratamentos não apresentaram diferenças, exceto 'Mundo Novo' enxertada sobre IAC 2258 (Tabela 6). 
Tabela 4. Comparações dos níveis de severidade ocasionados pela bactéria Xylella fastidiosa em cultivares de cafeeiro entre as regiões de Mococa (1998) e Garça (2000) no período de estresse hídrico (SP)

\begin{tabular}{|c|c|c|c|c|c|c|}
\hline \multirow{2}{*}{ Tratamentos } & \multicolumn{2}{|c|}{ Mococa } & \multicolumn{2}{|c|}{ Garça } & \multirow{2}{*}{$\mathrm{K} 1$} & \multirow{2}{*}{$\mathrm{P}$} \\
\hline & Mediana & $\mathrm{R}$ & Mediana & $\bar{R}$ & & \\
\hline Catuaí/IAC 2258 & 2,0 & 7,0 & 2,0 & 8,0 & 1,00 & $0,317 \mathrm{NS}$ \\
\hline Catuaí/ Bangelan & 1,5 & 7,5 & 1,5 & 7,5 & 0,00 & $1,000 \mathrm{NS}$ \\
\hline Catuaí/IAC 2286 & 2,0 & 7,5 & 2,0 & 7,5 & 0,00 & $1,000 \mathrm{NS}$ \\
\hline Mundo Novo/ IAC 2258 & 2,0 & 7,5 & 2,0 & 7,5 & 0,00 & $1,000 \mathrm{NS}$ \\
\hline Mundo Novo/Bangelan & 2,0 & 6,0 & 3,0 & 9,0 & 1,80 & $0,180 \mathrm{NS}$ \\
\hline Mundo Novo/IAC 2286 & 2,5 & 9,0 & 1,5 & 6,0 & 3,00 & $0,083 \mathrm{NS}$ \\
\hline Catuaí/ Catuaí & 2,5 & 9,5 & 1,5 & 5,5 & 4,00 & 0,046 * \\
\hline Mundo Novo/Mundo Novo & 2,0 & 7,5 & 2,0 & 7,5 & 0,00 & $1,000 \mathrm{NS}$ \\
\hline Mundo Novo & 2,5 & 8,0 & 1,5 & 7,0 & 0,2 & $0,655 \mathrm{NS}$ \\
\hline Catuaí & 3,0 & 9,5 & 2,0 & 5,5 & 4,00 & 0,046 * \\
\hline
\end{tabular}

Notas 1: $1 \%$ a $25 \%$ de ramos com sintomas (aparentemente sadia); $2:$ de $26 \%$ a $50 \%$ de ramos com sintomas (pouco infectada); 3: $51 \%$ a $75 \%$ de ramos com sintomas (moderadamente infectada); $4: 76 \%$ a $100 \%$ de ramos com sintomas (muito infectada). $\mathrm{R}$ = somatório do número de ordem; $\mathrm{K} 1$ = estatística $\mathrm{K}$ ajustado; $\mathrm{P}=$ probabilidade; ${ }^{*}=$ significativo a $5 \%$ pelo teste de Friedman; NS = não significativo.

Tabela 5. Comparações dos níveis de severidade ocasionados pela bactéria Xylella fastidiosa em cultivares de cafeeiro no período de estresse hídrico em Mococa em 1998 e em Garça em 2000 e 2002 (SP)

\begin{tabular}{|c|c|c|c|c|c|c|c|c|}
\hline \multirow{3}{*}{ Tratamentos } & \multirow{2}{*}{\multicolumn{2}{|c|}{$\begin{array}{c}\text { Mococa } \\
1998\end{array}$}} & \multicolumn{4}{|c|}{ Garça } & \multirow{3}{*}{ K1 } & \multirow{3}{*}{$\mathrm{P}$} \\
\hline & & & \multicolumn{2}{|c|}{2000} & \multicolumn{2}{|c|}{2002} & & \\
\hline & M & $\mathrm{R}$ & $\mathrm{M}$ & $\mathrm{R}$ & $\mathrm{M}$ & $\mathrm{R}$ & & \\
\hline Catuaí/ IAC 2258 & 2,0 & 11,0 & 2,0 & 12,5 & 1,0 & 6,5 & 6,5 & 0,039 * \\
\hline Catuaí/ Bangelan & 1,0 & 10,0 & 1,0 & 10,5 & 1,0 & 9,5 & 0,15 & $0,926 \mathrm{NS}$ \\
\hline Catuaí/IAC 2286 & 2,0 & 11,5 & 2,0 & 12,0 & 1,0 & 6,5 & 4,62 & $0,099 \mathrm{NS}$ \\
\hline M. Novo/ IAC 2258 & 2,0 & 11,0 & 2,3 & 10,5 & 1,7 & 8,5 & 0,88 & $0,646 \mathrm{NS}$ \\
\hline M. Novo/Bangelan & 2,0 & 9,0 & 3,0 & 13,5 & 2,0 & 7,5 & 4,59 & 0,101 NS \\
\hline M. Novo/IAC 2286 & 2,3 & 12,5 & 1,7 & 7,5 & 2,0 & 10,0 & 5,00 & $0,082 \mathrm{NS}$ \\
\hline Catuaí/ Catuaí & 3,0 & 14,0 & 2,0 & 8,0 & 2,0 & 8,0 & 6,86 & 0,032 * \\
\hline M. Novo/ M. Novo & 2,0 & 10,0 & 2,0 & 10,5 & 2,0 & 9,5 & 0,20 & $0,905 \mathrm{NS}$ \\
\hline M. Novo & 2,3 & 11,0 & 2,0 & 10,5 & 1,7 & 8,5 & 0,82 & $0,662 \mathrm{NS}$ \\
\hline Catuaí & 3,0 & 14,0 & 2,0 & 8,0 & 2,0 & 8,0 & 6,40 & 0,041 * \\
\hline
\end{tabular}

Notas 1: $1 \%$ a $25 \%$ de ramos com sintomas (aparentemente sadia); 2 : de $26 \%$ a $50 \%$ de ramos com sintomas (pouco infectada); 3: $51 \%$ a $75 \%$ de ramos com sintomas (moderadamente infectada); $4: 76 \%$ a $100 \%$ de ramos com sintomas (muito infectada). $\mathrm{R}$ = somatório do número de ordem; $\mathrm{K} 1=$ estatística $\mathrm{K}$ ajustado ; $\mathrm{M}=$ Mediana; $\mathrm{P}=$ probabilidade; ${ }^{*}=$ significativo a $5 \%$ pelo teste de Friedman; NS = não significativo. 
Tabela 6. Comparações dos níveis de severidade ocasionados pela bactéria Xylella fastidiosa em cultivares de cafeeiro entre o período de estresse hídrico e o chuvoso avaliado em 2000 e de 2002 em experimento localizado em Garça (SP)

\begin{tabular}{|c|c|c|c|c|c|c|}
\hline \multirow{2}{*}{ Tratamentos } & Mediana & $\mathrm{R}$ & Mediana & $\mathrm{R}$ & \multirow{2}{*}{ K1 } & \multirow{2}{*}{$\mathrm{P}$} \\
\hline & \multicolumn{2}{|c|}{ Estresse hídrico } & \multicolumn{2}{|c|}{ Chuvoso } & & \\
\hline \multicolumn{7}{|c|}{ Ano de 2000} \\
\hline Catuaí/IAC 2258 & 2,0 & 6,5 & 3,0 & 8,5 & 1,00 & $0,317 \mathrm{NS}$ \\
\hline Catuaí/ Bangelan & 1,5 & 7,0 & 1,5 & 8,0 & 0,33 & $0,564 \mathrm{NS}$ \\
\hline Catuaí/IAC 2286 & 2,0 & 6,0 & 3,0 & 9,0 & 3,00 & $0,083 \mathrm{NS}$ \\
\hline Mundo Novo/ IAC 2258 & 2,0 & 6,5 & 2,0 & 8,5 & 2,00 & $0,157 \mathrm{NS}$ \\
\hline Mundo Novo/Bangelan & 3,0 & 8,5 & 2,0 & 6,5 & 1,00 & $0,317 \mathrm{NS}$ \\
\hline Mundo Novo/IAC 2286 & 1,0 & 6,0 & 2,0 & 9,0 & 3,00 & $0,083 \mathrm{NS}$ \\
\hline Catuaí/ Catuaí & 1,0 & 5,0 & 3,0 & 10,0 & 5,00 & 0,025 * \\
\hline Mundo Novo/Mundo Novo & 2,0 & 5,5 & 3,0 & 9,5 & 4,00 & $0,046^{*}$ \\
\hline Mundo Novo & 2,0 & 5,5 & 3,0 & 9,5 & 4,00 & $0,046^{*}$ \\
\hline Catuaí & 1,5 & 6,0 & 2,5 & 9,0 & 3,00 & $0,083 \mathrm{NS}$ \\
\hline \multicolumn{7}{|c|}{ Ano de 2002} \\
\hline Catuaí/ IAC 2258 & 1,0 & 6,0 & 2,0 & 9,0 & 3,00 & $0,083 \mathrm{NS}$ \\
\hline Catuaí/ Bangelan & 1,0 & 7,0 & 2,0 & 8,0 & 0,20 & $0,655 \mathrm{NS}$ \\
\hline Catuaí/IAC 2286 & 1,0 & 6,0 & 2,0 & 9,0 & 3,00 & $0,083 \mathrm{NS}$ \\
\hline M. Novo/ IAC 2258 & 2,0 & 5,5 & 3,0 & 9,5 & 4,00 & $0,046^{*}$ \\
\hline Mundo Novo/Bangelan & 1,5 & 7,5 & 1,5 & 7,5 & 0,00 & $1,000 \mathrm{NS}$ \\
\hline Mundo Novo/IAC 2286 & 1,5 & 8,5 & 1,5 & 6,5 & 2,00 & $0,157 \mathrm{NS}$ \\
\hline Catuaí/ Catuaí & 3,0 & 7,5 & 3,0 & 7,5 & 0,00 & $1,000 \mathrm{NS}$ \\
\hline Mundo Novo/ Mundo Novo & 2,0 & 7,0 & 2,0 & 8,0 & 0,33 & $0,564 \mathrm{NS}$ \\
\hline Mundo Novo & 2,0 & 7,0 & 2,0 & 8,0 & 1,00 & $0,317 \mathrm{NS}$ \\
\hline Catuaí & 2,0 & 7,5 & 2,0 & 7,5 & 0,00 & $1,000 \mathrm{NS}$ \\
\hline
\end{tabular}

Notas 1: $1 \%$ a $25 \%$ de ramos com sintomas (aparentemente sadia); 2 : de $26 \%$ a $50 \%$ de ramos com sintomas (pouco infectada); 3: $51 \%$ a $75 \%$ de ramos com sintomas (moderadamente infectada); $4: 76 \%$ a $100 \%$ de ramos com sintomas (muito infectada). $\mathrm{R}$ = somatório do número de ordem; $\mathrm{K} 1$ = estatística $\mathrm{K}$ ajustado; $\mathrm{P}=$ probabilidade; ${ }^{*}=$ significativo a $5 \%$ pelo teste de Friedman; NS = não significativo.

Foram analisados os níveis de severidade incluindo todos os períodos amostrados em Garça (estresse hídrico e chuvoso) em 2000 e 2002 (Tabela 7). Observou-se que a 'Catuaí' enxertada sobre a $C$. canephora IAC 2286 apresentou maior severidade em 2000, recuperando-se em 2002. Do mesmo modo, 'Catuaí' enxertada sobre ela mesma, 'Mundo Novo' pé-franco e 'Mundo Novo' enxertada sobre ela mesma apresentaram sintomas mais severos no período de chuvas de 2000, recuperando-se nos dois períodos de 2002.

Tanto o período de chuvas como o de estresse hídrico coincidem com os períodos de maior atividade do cafeeiro, ou seja, floração e enchimento de grãos (formação do endosperma), respectivamente (CARELLI et al., 1989). Portanto, a planta necessita de um transporte rápido de água e nutrientes para as estruturas reprodutivas e órgãos fotossintéticos. Ademais, na fase de enchimento de grãos, esses acumulam cerca de $80 \%$ de água (CANNEL, 1975). A maior obstrução dos vasos do xilema, ocasionado pela $X$. fastidiosa no período de estresse hídrico, pode ser a causa do menor desenvolvimento dos frutos que se encontram em expansão.

O cafeeiro é uma planta de clima tropical úmido e temperaturas amenas, e as temperaturas médias anuais do ar mais favoráveis estão entre $18 \mathrm{e}$ $22{ }^{\circ} \mathrm{C}$, sendo os valores médios ideais entre 19 e $21^{\circ} \mathrm{C}$. 
Tabela 7. Comparações dos níveis de severidade ocasionados pela bactéria Xylella fastidiosa em cultivares de cafeeiro no período de estresse hídrico (P1) e chuvoso (P2) em Garça (SP) em 2000 e 2002

\begin{tabular}{|c|c|c|c|c|c|c|c|c|c|c|}
\hline \multirow{3}{*}{ Tratamentos } & \multicolumn{4}{|c|}{2000} & \multicolumn{4}{|c|}{2002} & \multirow{3}{*}{$\mathrm{K} 1$} & \multirow{3}{*}{$\mathrm{P}$} \\
\hline & \multicolumn{2}{|c|}{ P1 } & \multicolumn{2}{|c|}{ P2 } & \multicolumn{2}{|c|}{ P1 } & \multicolumn{2}{|c|}{ P2 } & & \\
\hline & $\mathrm{M}$ & $\mathrm{R}$ & $\mathrm{M}$ & $\mathrm{R}$ & $\mathrm{M}$ & $\mathrm{R}$ & $\mathrm{M}$ & $\mathrm{R}$ & & \\
\hline Catuaí/ IAC 2258 & 2,0 & 14,0 & 3,0 & 16,0 & 1,0 & 7,5 & 2,0 & 12,5 & 6,08 & $0,108 \mathrm{NS}$ \\
\hline Catuaí/ Bangelan & 1,4 & 12,0 & 1,6 & 14,0 & 1,4 & 10,5 & 2,1 & 13,5 & 1,18 & $0,757 \mathrm{NS}$ \\
\hline Catuaí/IAC 2286 & 2,0 & 13,5 & 3,0 & 18,5 & 1,0 & 6,5 & 2,0 & 11,5 & 11,68 & $0,009 * *$ \\
\hline M. Novo/ IAC 2258 & 2,1 & 11,0 & 2,4 & 15,5 & 1,4 & 8,0 & 2,6 & 15,5 & 5,79 & $0,123 \mathrm{NS}$ \\
\hline M. Novo/Bangelan & 2,7 & 17,0 & 2,3 & 14,5 & 1,5 & 9,0 & 1,5 & 9,5 & 7,00 & $0,072 \mathrm{NS}$ \\
\hline M. Novo/IAC 2286 & 1,5 & 10,0 & 2,3 & 16,0 & 1,7 & 14,0 & 1,5 & 10,0 & 6,23 & $0,101 \mathrm{NS}$ \\
\hline Catuaí/ Catuaí & 1,1 & 9,5 & 2,9 & 20,0 & 1,1 & 9,5 & 1,4 & 11,0 & 11,77 & $0,008^{* *}$ \\
\hline M. Novo/ M. Novo & 2,0 & 11,0 & 3,0 & 18,5 & 2,0 & 9,5 & 2,0 & 11,0 & 7,62 & $0,055^{*}$ \\
\hline M. Novo & 2,1 & 12,0 & 3,1 & 19,5 & 1,4 & 8,5 & 1,9 & 10,0 & 10,46 & $0,015 * *$ \\
\hline Catuaí & 2,0 & 11,0 & 3,0 & 17,5 & 2,0 & 10,5 & 2,0 & 11,0 & 6,70 & $0,082 \mathrm{NS}$ \\
\hline
\end{tabular}

Notas 1: $1 \%$ a $25 \%$ de ramos com sintomas (aparentemente sadia); 2 : de $26 \%$ a $50 \%$ de ramos com sintomas (pouco infectada); 3: $51 \%$ a $75 \%$ de ramos com sintomas (moderadamente infectada); $4: 76 \%$ a $100 \%$ de ramos com sintomas (muito infectada). $\mathrm{R}$ = somatório do número de ordem; $\mathrm{K} 1$ = estatística $\mathrm{K}$ ajustado; $\mathrm{M}=$ Mediana; $\mathrm{P}=$ probabilidade; ${ }^{*}$, ${ }^{* *}=$ significativo a $5 \%$ e $1 \%$ pelo teste de Friedman respectivamente; NS = não significativo.

O clima de Garça é subtropical, de temperatura máxima de $28,5^{\circ} \mathrm{C}$ e mínima de $17,8^{\circ} \mathrm{C}$. $\mathrm{O}$ índice pluviométrico é de $1.274,4 \mathrm{~mm}$ por ano. $\mathrm{O}$ período mais quente ocorre de dezembro a março, com temperatura oscilando entre 25 e $30^{\circ} \mathrm{C}$, coincidindo com a época mais chuvosa do ano. Temperaturas mais amenas ocorrem entre abril e julho. Mococa se caracteriza por uma temperatura média anual entre 16,4 e $28,3^{\circ} \mathrm{C}$. Tanto Mococa como Garça possuem temperaturas médias mínimas e máximas superiores às desejáveis para a cultura do café. O período de estresse hídrico é sempre mais acentuado em Mococa, porém na época de chuvas, ocorre pluviosidade média maior em Garça.

As diferenças da severidade da X. fastidiosa têm sido atribuídas a diferentes raças por alguns autores (Hopkins, 1984; PoOler e HarTUng, 1995a, b), e outros acreditam que as diferenças sejam devidas a variações climáticas, porque no caso da cultura de citros, produzida sem irrigação, os sintomas mais severos ocorreram na Região Norte do Estado, onde a estação seca foi prolongada (QIN et al., 2001). Neste trabalho, pelas Tabelas 1 a 3, observaram-se variações de notas de sintomas de severidade de 1 a 4 entre as parcelas de uma mesma cultivar desenvolvida nas mesmas condições edafoclimáticas, tratos culturais e manejo. Essas variações não poderiam ser atribuídas apenas ao fator clima, mas concordam com as especulações de outros autores na literatura que existem diferentes raças da bactéria ou que as diferenças de resistência ou tolerância do cafeeiro devem-se à alta variabilidade genética dentro de uma mesma cultivar. Hopkins (1984), Fry E Milholland (1990) e Oliveira e Vallim (2002) acreditam que a intensidade do sintoma esteja relacionada com a concentração da bactéria, enquanto EVERT E Muluinix JR. (1983) ressaltam que os sintomas externos conhecidos dos ramos e frutos do pessegueiro infectado são provocados pelo estresse hídrico resultante da transpiração.

A interação Xylella-hospedeiro é muito complexa, havendo opiniões divergentes entre os autores e culturas. ESAU (1948), MIRCETICH et al. (1976) e Mollenhauer e Hopkins (1976) consideram que a causa principal dessa doença está relacionada com a disfunção no sistema condutor de água devido às oclusões dos vasos do xilema por "gomas", tiloses ou células bacterianas; outros autores acreditam que essas obstruções são insuficientes para causar um estresse hídrico (Mircetich et al., 1976; French e STASSI, 1978 e HopkINS, 1981). Outras duas hipóteses para a origem dos sintomas da doença são a da fitotoxina (Mircetich et al., 1976 e Lee et al., 1982) e a do desbalanço de reguladores de crescimento (FRENCH e StASSI, 1978) que ocasionavam os sintomas na planta provocados pela bactéria. 
A seca ocorrida em Garça em 2002 foi muito mais prolongada e severa do que a de 2000 e a de 1998, em Mococa. Porém, a severidade no ano de 2002 em Garça foi menor em relação às demais, demonstrando que o déficit hídrico não é o único fator determinante dos sintomas externos da presença da bactéria, mas que outros fatores de estresse fisiológicos ou ambientais provavelmente interagem na resposta da planta.

\section{CONCLUSÕES}

1. Não houve diferenças no nível de severidade de sintomas entre as cultivares avaliadas em Mococa e Garça no período de estresse hídrico.

2. No período chuvoso, o sintoma foi mais severo em 2000 nas cultivares Catuaí e Mundo Novo não enxertadas em relação às enxertadas; entretanto, em 2002, não houve diferenças entre elas.

3. A 'Catuaí' não enxertada apresentou severidade maior em Mococa do que em Garça.

4. Comparando-se os dois períodos de estresse hídrico e de chuvas ao longo de $2000 \mathrm{em}$ Garça, 'Catuaí' enxertada sobre ela mesma e 'Mundo Novo' pé-franco e 'Mundo Novo' enxertada sobre ela mesma apresentaram um aumento na severidade no período de chuvas; em 2002, houve aumento na severidade apenas na 'Mundo Novo' enxertada sobre C. canephora IAC 2258.

5. A disponibilidade de água no solo não é a causa única do aparecimento do sintoma, mas provavelmente interage com outros fatores ambientais ou fisiológicos para a expressão do sintoma da doença.

\section{AGRADECIMENTOS}

Ao pesquisador científico do IAC, aposentado, Armando Conagin, pela orientação nas análises estatísticas. Ao proprietário da Fazenda da Mata, Sr. Nizio Bonini e aos Engenheiros Agrônomos da GARCAFÉ, Gustavo Guerreiro e José Antônio de Mendonça Otoboni, pelo manejo da cultura.

\section{REFERÊNCIAS}

CARELLI, M.L.C.; FAHL, J.I.; MAGALHÃES, A.C. Assimilação de nitrato durante o desenvolvimento reprodutivo de plantas de café. Revista Brasileira de Ciência do Solo, Campinas, v.13, p.59-64, 1989.
CANNEL, M.G.R. Crop physiological aspects of coffee bean yield: a review. Journal of Coffee Research, Karnataka, v.5, p.7-20, 1975.

CHAGAS, C.M.; ROSSETTI, V.; BERETTA, M.J.G. Electron microscopy studies of xylem-limited bacterium in sweetorange affected with Citrus variegated chlorosis disease in Brazil. Journal of Phytopathology, Berlin, v.34, p.306-312, 1992.

ESAU, K. Anatomic effects of the viruses of pierce's disease and phony peach. Hilgardia, Berkeley,v.18,n.12, p.423-482, 1948.

EVERT, D.R.; MULLINIX Jr., B.G. Xylem water potential of peach trees infected with phony disease. HortScience, Alexandria, v.18, p.719-721, 1983.

FAHL, J.I.; CARELLI, M.L.C.; GALLO, P.B.; COSTA, W.M.; NOVO, M.C.S.S. Enxertia de Coffea arabica sobre progênies de C. canephora e de C. congensis no crescimento, nutrição mineral e produção. Bragantia, Campinas, v.57, n,2, p.297-312, 1998.

FAHL, J.I.; CARELLI, M.L.C.; MENEZES, H.C.; GALLO, P.B.; TRIVELIN, P.C.O. Gas exchange, growth, yield and beverage quality of Coffea arabica cultivars grafted on to C. canephora and C. congensis. Experimental Agriculture, London, v.37, p.241252, 2001.

FRENCH, W.J.;STASSI, D.L. Response of phony- infected peach trees to gibberellic acid. HortScience, Alexandria, v.13, n.2, p.158-159, 1978.

FRY, S.M.; MILHOLLAND, R.D. Multiplication and translocation of Xylella fastidiosa in petioles and stems of grapevine resistant, tolerant, and susceptible to Pierce's disease. Phytopathology, St. Paul, v.80,n.1, p.61-65, 1990.

GOHEEN, A.C.; NYLAND, G.; LOWE, S.K. Association of a rickettsia-like organism with Pierce's disease of grapevines and alfalfa dwarf and heat therapy of the disease in grapevines. Phytopathology, St. Paul, v.63, p.341-345, 1973.

GOMES, F.P. Curso de Estatística Experimental. 13.ed. Piracicaba, Livraria Nobel, 1990. 468p.

HOPKINS, D.L. Seasonal concentration of the Pierce's disease bacterium in grapevine stems, petioles and leaf veins. Phytopathology, St. Paul, v.71, p.415-418, 1981.

HOPKINS, D.L. Variability of virulence in grapevine among isolates of the Pierce's disease bacterium. Phytopathology, St. Paul, v.74, n.11, p.1395-1398, 1984.

HOPKINS, D.L. Xylella fastidiosa: xylem-limited bacterial pathogen of plants. Annual Review Phytopathology, Palo Alto, v.27, p.271-290, 1989.

HOPKINS, D.L.; MOLLENHAUER, H.A.; FRENCH, W. J. Occurrence of a rickettsia-like bacterium in the xylem of peach trees with phony disease. Phytopathology, St. Paul, v.63, p.1422-1423, 1973.

HOPKINS, D.L;. ADLERZ, W.C. Natural hosts of Xylella fastidiosa in Florida. Plant Disease, St. Paul, v.72, p.429-431, 1988. 
LEE, R.F.; RAJU, B.C.; NYLAND, G.; GOHEEN, A.C. Phytotoxin (s) produced in culture by the Pierce's disease bacterium. Phytopathology, St. Paul, v.72, p.886-888, 1982.

LIMA, J.E.O.; MIRANDA, V.S.; HARTUNG, J.S.; BRLANSKY, R.H.; COUTINHO, A.; ROBERTO, S.R.; CARLOS, E F. Distribuição da Xylella fastidiosa no cafeeiro, nas regiões cafeeiras e seu isolamento "in vitro". Fitopatologia Brasileira, Brasília, v.21, n.3, p.392-393, 1996.

LOPES, J.R.S. Mecanismos de transmissão de Xylella fastidiosa por cigarrinhas. Laranja, Cordeirópolis, v.17, n.1, p.79-92, 1996.

MIRCETICH, S.M. ; LOWE, S.K., MOLLER, W.J.; NYLAND, G. Etiology of almond leaf scorch disease and transmission of the causal agent. Phytopathology, St. Paul, v.66, p.17-24, 1976.

MOLLENHAUER, H.A.; HOPKINS, D.L. Xylem morphology of Pierce's disease-infected grapevines with different levels of tolerance. Physiological Plant Pathology, New York, v.9, p.95-100, 1976.

NYLAND, G.; GOHEEN, A.C.; LOWE, S.K.; KIRKPATRICK, H.C. The ultrastructure of a rickettsia-like organism from a peach tree affected with phony disease. Phytopathology, St. Paul, v.63, p.1255-1258, 1973.

OLIVEIRA, A.C.; VALLIM, M.A. Quantification of Xylella fastidiosa from Citrus trees by real-time polymerase chain reaction assay. Phytopathology, St. Paul, v.92, n.10, p.10481054, 2002.

PAIVA, P.E.B.; SILVA, J.L. da; GRAVENA, S.; YAMAMOTO, P.T. Cigarrinhas de xilema em pomares de laranja do Estado de São Paulo. Laranja, Cordeirópolis, v.17, n.1, p.41-54, 1996.

PARADELA FILHO, O.; SUGIMORI, M.H.; RIBEIRO, I.J.A.; GARCIA Jr., A.; BERETTA, M.J.G.; HARAKAWA, R.; MACHADO, M.A.; LARANJEIRA, F.F.; RODRIGUES NETO, J.; BERIAM, L.O.S. Primeira constatação em cafeeiro no Brasil da Xylella fastidiosa causadora da clorose variegada dos citros. Laranja, Cordeirópolis, v.16, n.2, p.135-136, 1995.

PARADELA FILHO, O.; SUGIMORI, M.H.; RIBEIRO, I.J.A.; MACHADO, M.A.; LARANJEIRA, F.F.; GARCIA JUNIOR, A.; BERETTA, M.J.G.; HARAKAWA, R.; RODRIGUES NETO, J.; BERIAM, L.O.S. Constatação da Xylella fastidiosa em cafeeiro no Brasil. Summa Phytopathologica, Jaboticabal, 23:46-49, 1997.
PIERCE, N.B. The California Vine Disease. Colorado: U.S. Department of Agriculture, 1892. 222p. (Division of Vegetal Pathology Bulletin, n.2)

PRATO, J.R.A. Quem diria, a Xylella fastidiosa sempre esteve no café. A Granja, v.614, p.40-43, 2000.

POOLER, M.R.; HARTUNG, J.S. Specific PCR detection and identification of Xylella fastidiosa strains causing citrus variegated chlorosis. Current Microbiology, New York, v.31, p.377-381, 1995a.

POOLER, M.R.; HARTUNG, J.S. Genetic relationship among strains of Xylella fastidiosa from RAPD-PCR data. Current Microbiology, New York, v. 31, p.134-137, 1995 b.

QIN, X.; MIRANDA, V.S.; MACHADO, M.A.; LEMOS, E.G.M.; HARTUNG, J.S. An evaluation of the genetic diversity of Xylella fastidiosa isolated from diseases citrus and coffee in São Paulo, Brazil. Phytopathology, St. Paul, v.91, n.6, p.599-605, 2001.

QUEIROZ-VOLTAN, R.B.; PARADELA FILHO, O.; CARELLI, M.L.C.; FAHL, J.I. Aspectos estruturais de cafeeiro infectado com Xylella fastidiosa. Bragantia, Campinas, v.58,n.1, p.23-33, 1998.

QUEIROZ-VOLTAN, R.B.; FAHL, J.I; CARELLI, M.L.C.; PARADELA FILHO, O.; SUGIMORI, M.H.; GALLO, P.B. Relação entre os sintomas morfológicos externos de cafeeiro infectado pela Xylella fastidiosa e a porcentagem de obstrução dos vasos do xilema. In: I SIMPÓSIO DE PESQUISA DOS CAFÉS DO BRASIL, Poços de Caldas, 2000. Anais... Brasília. Consórcio Brasileiro de Pesquisa e Desenvolvimento do Café, 2000. V.1, p.241-244.

RAIJ, B.van; CANTARELLA, H.; QUAGGIO, J.A. Estimulantes. In: RAIJ, B.van; CANTARELLA, H.; QUAGGIO, J.A.; FURLANI, A.M.C. (Eds.). Recomendações de adubação e calagem para o Estado de São Paulo. 2.ed. Campinas, Instituto Agronômico \& Fundação IAC, 1997. 285p. (Boletim técnico, 100).

SPRENT, P. Applied Nonparametric Statistical Methods. 2.ed. London: Chapman \& Hall, 1996. 342p. 